\title{
Pobreza, emoção e saúde: uma discussão sobre pentecostalismo e saúde no Brasil*
}

Victor Vincent Valla

Fundação O swaldo Cruz, Escola Nacional de Saúde Pública Universidade Federal Fluminense, Faculdade de Educação

\section{Introdução}

No momento que este texto está sendo elaborado, os jornais noticiam o início de longo crescimento econômico no Brasil, com o governo federal apontando com otimismo para uma luz no fim de um túnel longo e escuro. No entanto, uma leitura mais cuidadosa, além das manchetes, revela que crescimento econômico juntamente com produção e exportação maiores não significam necessariamente melhoras nas condições de vida das classes populares. Dentro do que se chama de modelo "capitalista técnico-científico", através de uma tecnologia poupadora de mão-deobra - automação juntamente com informática, que se modifica com mais rapidez a cada ano -, está sendo gestado o que alguns chamam de desemprego estrutural. Isso significa que, quando muitos perdem seus empregos, não são necessariamente substituídos por

* Trabalho preparado para a sessão especial "Educação, Movimentos Sociais e Religião", na 24 ${ }^{a}$ Reunião Nacional da ANPEd (Caxambu, MG, de 7 a 11 de outubro de 2001). Não chegou a ser apresentado, por problema de saúde do autor. outros trabalhadores, mas que as vagas até então ocupadas desaparecem.

Aumenta então o número de pessoas que não têm acesso ao emprego. Não entram em discussão termos como "preguiça", "fazer um esforço para achar um emprego", pois simplesmente não existem mais empregos com garantias sociais de previdência, férias, horas extras etc. para grande número de brasileiros ou, se quisermos, latino-americanos. Até o trabalho remunerado, mas sem garantias sociais, está ficando raro, fazendo com que seu valor tenda a diminuir.

Se até hoje ouvimos os pobres dizerem que dificilmente sua situação mudará durante sua vida, atualmente cresce o número de intelectuais e pesquisadores que começam a concordar com o que era compreendido como "pessimismo" de quem não estudou suficientemente. Hoje essa situação tem um nome: miséria radical, e não há evidências de que a situação dos pobres se modificará, principalmente em um país onde o governo federal utiliza 65\% do Produto Interno Bruto para pagar a dívida externa. Em debate recente, a secretária municipal de educação de um governo do Partido dos Trabalhadores explicou para uma platéia 
de alunos por que os mandatos do PT eram tão premiados pela UNESCO: os governos petistas sabiam melhor desconcentrar a miséria, distribuir a pobreza... mas não eliminá-la.

Instrumentos históricos como a "revolução" ou a "transição para o socialismo" tendem a ser vistos como quase impossíveis, devido à hegemonia norte-americana na economia e no campo militar. Alguns analistas políticos vêem a Guerra do Golfo como demonstração de força do governo norte-americano no mundo sem a União Soviética, mais do que como um gesto de defesa do Kuwait contra a agressão do Iraque. Outros entendem que o Plano Colômbia não seria apenas uma proposta militar norte-americana para tentar abafar o movimento dos exércitos revolucionários na Colômbia, mas o ponto de partida para a "internacionalização" da Amazônia e para maior controle das economias e vidas políticas dos países latino-americanos, através do Banco Mundial e do Fundo Monetário Internacional.

No entanto, a análise da conjuntura atual não pode ser vista como convite ao pessimismo, mas apontando que as mudanças que ocorrerão na sociedade latino-americana, e em particular no Brasil, têm de ser pensadas neste contexto, e não no contexto que gostaríamos que viessem a acontecer, acreditando que a saída dessa crise passa justamente pelas classes populares.

\section{Situando a saúde pública neste contexto}

À luz da discussão acima apresentada, podemos pensar o quadro da saúde pública do país e as condições de saúde das classes populares. Certamente, a vasta rede de saúde pública, composta de centros

\footnotetext{
${ }^{1}$ Reconhecido como um dos mais importantes cientistas do mundo, Milton Santos fez a seguinte afirmação em palestra que realizou, pouco antes de sua morte, na Escola Nacional de Saúde Pública, da Fundação Oswaldo Cruz: "Na reconstrução do Brasil, cabe a crença de que o caminho a ser seguido vai ser indicado pelas classes populares".
}

municipais de saúde e de hospitais públicos, é de importância fundamental no atendimento às classes populares. A demanda, no entanto, é tão grande que questões como o acesso a serviços e a resolutibilidade das queixas, fazem com que as consultas tenham uma duração de aproximadamente cinco minutos. Por essa razão, os profissionais têm condições limitadas de atender a um problema que vem sendo levado pelas classes populares aos serviços de saúde: a queixa designada pelo nome de "sofrimento difuso", apresentada, segundo alguns profissionais, por seis em cada dez pacientes. Não se trata de uma queixa nova, mas de algo que está crescendo no país. Queixa sobre dores de cabeça, dores em outros locais do corpo, medo, ansiedade - sintomas para os quais o sistema de saúde não dispõe nem de tempo, nem de recursos para tratar. O resultado é a medicalização do problema. $\mathrm{Na}$ Argentina, a doutora Sylvia Bermann (1995) constatou que mais de $50 \%$ dos medicamentos indicados são psicofármacos (no Brasil, alguns especialistas calculam que a porcentagem é mais alta), para tratar o que as classes alta e média chamam de ansiedade ou estresse, e as classes populares chamam de "nervos".

Há, então, determinados limites do alcance do sistema de saúde pública, fazendo com que a população busque outras saídas para as suas queixas. Como diz Luz (1996), ninguém, na realidade, está satisfeito com os serviços de saúde, sejam públicos ou privados, mas as classes alta e média têm mais recursos para lidar com suas queixas.

\section{Apoio social e saúde}

Nos Estados Unidos e na Europa, problemas semelhantes vêm ocorrendo há alguns anos. Alguns profissionais norte-americanos, preocupados com a insatisfação manifestada pela população relativamente aos serviços públicos de saúde naquele país, vêm desenvolvendo experiências e investigações sobre outras concepções da relação entre saúde e doença. $\mathrm{O}$ atual modelo biomédico, hegemônico nos Estados Unidos e no Brasil, teve sua origem na descoberta de como 
lidar e superar as doenças que surgiram a partir de infecções e, como todos sabem, obteve muito sucesso. O problema, como Ivan Illich constatou anos atrás, é que a medicalização da infecção acabou sendo o caminho apontado para a cura de muitas queixas, produzindo o que alguns chamam hoje de "medicalização da sociedade", sem necessariamente resolver problemas como o do "sofrimento difuso". Na tentativa de solucionar esse problema, foram levantadas algumas hipóteses; uma delas é que a origem das doenças, em um primeiro momento, estaria muito mais relacionada com as emoções do que com bactérias ou com vírus.

Goleman (1995) afirma que, segundo a tradição budista tibetana, a doença surge a partir do desequilíbrio no corpo psicofísico produzido por emoções conflitantes como a raiva ou a ganância. O raciocínio desenvolvido é que uma relação desequilibrada entre os homens e o meio ambiente (entendendo-se nesse pensamento que os homens também fazem parte do meio ambiente) seria o responsável pelo surgimento da doença. Mais do que a entrada de uma bactéria ou de um vírus no corpo humano, o início de uma doença estaria relacionado com uma reação emocional do homem ou da mulher, hoje causado freqüentemente pelo que se chama de estresse. A doutora Sylvia Bermann (1995) nos aconselha, no entanto, a não deixar a palavra estresse escamotear questões importantes, especialmente em relação às classes populares. Há o perigo de transformá-la em um termo genérico, fazendo com que todos aparentemente sofram de estresse da mesma forma, quando na realidade há uma grande diferença entre uma pessoa rica perder muito dinheiro na bolsa de valores e um pobre tentar dormir sabendo que provavelmente haverá um tiroteio entre narcotraficantes e a polícia, perto do seu barraco, na favela.

Segundo o doutor B. S. McEwen (1998), o estresse é causado por um estilo de vida em que as pessoas estão sistematicamente expostas a agressões de ordem física e psíquica. O "susto contínuo", comum às classes populares que vivem em condições de pobreza e violência, ainda segundo McEwen, faz com que grandes quantidades de adrenalina sejam lançadas no corpo, quando isto só deveria ocorrer em momentos especiais, em situações de emergência para o indivíduo.

Trabalhar 10 a 12 horas por dia num ambiente insalubre, sem carteira assinada, sem proteção social de um plano de saúde e sem garantia de que o trabalho executado vai continuar amanhã é um processo de estresse que provavelmente terminará em doença. Os estudiosos dessa hipótese levantam a idéia de que o desequilíbrio emocional produzido pelo estresse tende a se concentrar em um órgão do corpo e, à medida que o estresse se manifesta, castigar esse órgão. As filosofias orientais corroboram essa visão, afirmando que há relação dos órgãos com os sentimentos, que determinadas doenças se relacionam com determinados sentimentos - por exemplo: o fígado com a raiva, os pulmões com a tristeza, os rins com o medo.

Os investigadores responsáveis pela elaboração da teoria do apoio social trabalham com a premissa de que, se a origem da doença está relacionada com a questão das emoções, sua resolução também estaria relacionada com as emoções, o que indica que essa teoria inclui a idéia antiga da unidade corpo-mente. A proposta central do apoio social é que, quando as pessoas sentem que contam com o apoio de um grupo de pessoas (associação, vizinhança, igreja, por exemplo), isso tem o efeito de causar melhora em sua saúde. Esse apoio normalmente ocorre, de forma sistemática, entre pessoas que se conhecem, razão pela qual freqüentemente envolve uma instituição ou entidade como pano de fundo.

Uma das primeiras experiências com essa proposta ocorreu há alguns anos, na Cidade de Guatemala, em uma grande maternidade que fazia em torno de 24 partos diariamente. Separadas as gestantes em dois grupos, foi oferecido a um dos grupos de 12 mulheres uma acompanhante, trazida de um bairro popular da cidade. Sem qualquer orientação, a não ser "tomar conta da gestante", a acompanhante cuidava das mulheres no dia anterior ao parto, no dia do parto e no dia após o parto. Mesmo com as gestantes não tendo conhecimento prévio dessa acompanhante, os resultados foram surpreendentes: os partos foram mais bem- 
sucedidos e houve menos problemas para as gestantes que foram acompanhadas. Experiências semelhantes ocorrem hoje, através de voluntárias, em hospitais públicos de São Paulo.

No início das investigações relativas à teoria do apoio social, deu-se muita atenção à vida dos idosos nos Estados Unidos. Descobriu-se então que uma pessoa da terceira idade com condições satisfatórias de saúde provavelmente contrairia uma doença a partir de determinados baques emocionais - como, por exemplo, a perda do(a) companheiro(a), a descoberta da incapacidade de trabalhar, ou a perda da residência onde havia morado durante décadas. Os idosos inseridos em redes de apoio social tinham menos oportunidade de adoecer a partir desses eventos de vida, por contarem com um apoio emocional contínuo. Podese deduzir que, se ocorrem esses tipos de eventos de vida para idosos de um país desenvolvido, eles seriam também comuns a grandes parcelas das classes populares, em uma região como a América Latina e em um país como o Brasil: perda de entes queridos por violência, crescentes índices de desemprego ou trabalho com remuneração vil e a conseqüente situação de não contar com residência própria e tampouco fixa.

A lógica que está por trás da teoria do apoio social é a mesma que sustenta as chamadas propostas alternativas de saúde. ${ }^{2}$ Praticamente todas as pessoas sofrem de uma forma ou outra do fenômeno de estresse. Por contar com mais recursos, as classes média e alta buscam saídas para suas queixas de "sofrimento difuso" que geralmente não são acessíveis às classes populares. A maioria das propostas conhecidas como "alternativas" - meditação, yoga, tai chi chuan, terapias das mais variadas formas - é normalmente oferecida na esfera privada e custam preços que as classes populares não podem pagar. Além disso, as próprias terapias propostas seguem geralmente uma

2 Fala-se "chamadas propostas alternativas" porque a palavra "alternativa" suporia que há uma referência para a qual outras propostas seriam alternativas. Na verdade, o modelo biomédico é apenas uma das propostas existentes sobre a relação saúde-doença. lógica voltada para as condições de vida das classes média e alta.

Embora não se pretenda negar os processos de estresse que ocorrem em membros das classes médias e altas, é fundamental ressaltar que as classes populares nas grandes cidades tendem a sofrer um processo de estresse muito mais intenso. A vereadora Jurema Batista, do Rio de Janeiro, pergunta se há remédio para pressão arterial alta quando o helicóptero da Polícia Militar sobrevoa a favela procurando componentes do narcotráfico. Um engarrafamento no trânsito pode significar pequenas irritações para as classes médias, mas para o morador da favela a origem do estresse está freqüentemente relacionada, por exemplo, com a falta de água contínua, as quedas freqüentes na voltagem elétrica e consequiente danificação dos eletrodomésticos, ou com a violência.

O estresse é causado pelo que os profissionais chamam de "superexcitação do organismo", e "carga alostática" é o nome que McEwen (1998) dá ao conjunto de indicadores de estresse. Importa nesta discussão que grande parcela das classes populares está exposta ao que é chamado por Valla (1999b) de "estado de emergência permanente". A grande imprensa tende a definir o termo "emergência" como um acontecimento passageiro - um blecaute ou uma enchente, por exemplo. Uma vez que a água deixe de cobrir os automóveis, ou que a luz elétrica volte, para a grande imprensa terminou a emergência. Mas para muitos moradores de favela, as condições de vida indicam este estado de emergência permanente: distribuição irregular de água, difícil acesso às unidades de saúde, exposição permanente às balas "perdidas", ou ganhar a sobrevivência através do mercado informal em processo de saturação.

Em um país onde os serviços de saúde são fortemente moldados pelo modelo biomédico, dificilmente as atividades propostas na área de saúde alternativa ocorrem no setor público; em geral exige-se algum tipo de pagamento. Embora não seja impossível que atividades de apoio social sejam desenvolvidas em unidades de saúde pública - grupos de discussão, relaxamento muscular ou meditação -, profissionais de 
saúde mais críticos afirmam que esse tipo de atividade é visto por muitos colegas como forma de "fugir do trabalho".

Uma das propostas para o combate ao estresse é a introspeção e meditação. Embora teoricamente a prática de meditação não seja impossível qualquer que seja a circunstância, é evidente que um lugar relativamente espaçoso e quieto facilita a concentração. Normalmente, o período de meditação mais curto, uma hora, é dividido em duas partes: meia hora para ouvir uma leitura que facilite a passagem da agitação da rua para a quietude da sala de meditação e meia hora de meditação de fato. Uma tarefa difícil para quem trilha o que Chaui (1990) chama de o "caminho estreito", isto é, uma vida de pouco dinheiro, espaço e tempo livre.

Salvo engano, não está muito desenvolvida no Brasil a discussão do que seria uma dieta moderada e prudente para as classes populares, levando em conta os custos e as questões culturais. As recomendações que os médicos fazem sobre uma dieta moderada e prudente, como também de exercício físico sistemático, esbarram em obstáculos relacionados com as condições de vida das classes populares. Jogar futebol nos domingos à tarde não parece corresponder à idéia de exercício físico sistemático. Mesmo assim, McEwen (1998) lembra que essas recomendações, em muitos casos, não são suficientes, se não houver como agir na causa imediata do problema, pois o estresse tem causas sociais complexas, que não podem ser resolvidas pela medicina, como a pobreza, más condições de trabalho ou o ambiente poluído. McEwen acrescenta que pesquisas mostram que, quanto mais pobre for uma pessoa, pior é a sua saúde, não importando se ela tem ou não acesso a tratamento médico.

Como ser menos competitivo e ansioso (outra recomendação dos terapeutas para reduzir o estresse) em um mundo onde as ofertas do trabalho formal estão rapidamente declinando e onde o mercado informal está se saturando? Ainda como recomendação genérica, alguns terapeutas chamam a atenção para a importância do desabafo e do "não engolir sapos" para expulsar o veneno do corpo, evitando que ele se acu- mule e precise ser expulso de outras formas. Mas o que pode significar "engolir sapos" ou desabafar, para a maioria da população? Desabafar na hora pode resultar em vários desfechos para as classes populares: pode significar perder o emprego, seja no trabalho da fábrica, seja como empregada doméstica. Em uma cultura machista, desabafar na hora, ou seja "não engolir sapo", "não levar desaforo para casa", pode terminar em enfrentamento com final incerto.

Parece evidente que a crise do "acesso aos serviços" é apenas um dos problemas que os pobres enfrentam com relação à saúde. Se a prevenção, o tratamento e a recuperação não são apenas questões do corpo, e sim, como propõe a teoria do apoio social, questões da unidade corpo-mente, ou, se preferirmos, da unidade corpo-alma, é muito provável que hoje a grande procura das camadas populares pelas igrejas signifique alguma espécie de busca de solução dessas questões.

\section{Relacionando o apoio social com a religiosidade popular via o fenômeno da emoção}

Há que se ter cuidado com a interpretação das ações das classes populares e sua relação com a religião, pois o que pode ser visto como tentativa de resolver um problema exclusivamente material pode bem ser o resultado da vontade de viver a vida da forma mais plena possível. Pode ser também o resultado da procura de explicação, de algo que faça a vida ter mais sentido e ser mais coerente - que é justamente uma das propostas do apoio social.

É assim que cabe considerar esse apoio social como uma das explicações do extraordinário crescimento da presença das classes populares nas igrejas de todas as religiões, mas principalmente nas chamadas "evangélicas" ou "pentecostais". Atrás dessa procura está também o processo do crescimento da urbanização, o conseqüente aumento das demandas dos bens coletivos e individuais e, ao mesmo tempo, a dilapidação dos direitos sociais e humanos. Machado 
(1996) observa que a falta de apoio institucional, nesta época de mudanças sociais intensas, faz com que as igrejas ofereçam um "potencial racionalizador", isto é, um sentido para a vida. Por sua vez, Mariz e Machado (1994) comentam a frágil presença dos partidos políticos, de associações e do próprio Estado do bem-estar entre os pobres, e como as religiões oferecem alguns grupos de suporte alternativos e criam motivações para enfrentar a pobreza.

Assim, a busca de grandes parcelas das classes populares pelo alívio dos seus sofrimentos e, simultaneamente, a procura da solidariedade e conforto do apoio social denotam que, nas palavras de Fernandes (1994), "abaixo da linha d'água, move-se um vasto conjunto heteróclito de articulações... em contextos de religiosidade e magia que são não-governamentais, sem fins lucrativos e, no entanto, informais" (p. 26). Neste contexto, a palavra "alívio" pode ser compreendida em dois sentidos: alívio temporário do sofrimento físico e mental e alívio do processo do estresse que castiga determinado órgão do corpo.

Certamente alguns líderes religiosos procuram utilizar suas igrejas como forma de enriquecer ou de angariar votos para seus candidatos. No entanto, isto não explica satisfatoriamente o porquê de tantos brasileiros estarem procurando as igrejas, em particular as evangélicas e pentecostais. Quantos outros grupos no Brasil gostariam de fazer o mesmo com as classes populares e não conseguem? É necessário procurar outra explicação, que relativize a participação dos líderes religiosos. Possivelmente poderia ser o que Finkler chama de "símbolos emocionalmente densos, derivados da experiência coletiva daqueles que sofram" (apud Fernandes, 1994, p. 110-111). A respeito do sucesso das curas espirituais de sofrimentos crônicos, de uma forma que a biomedicina não é capaz de igualar, Finkler (1985) refere-se aos quinhentos centros espiritualistas e cinco milhões de fiéis no México. Os trabalhos desenvolvidos nesses centros atenuam a dor, quando não a eliminam, e ajudam as vítimas do sofrimento a tornar suas vidas mais toleráveis e significativas. Aqui é possível se referir novamente à discussão do apoio social, no qual "tornar a vida mais significativa" remete ao "controle sobre seu próprio destino" e a ver "mais coerência e sentido na sua própria vida". Caberia perguntar, inclusive, dentro da perspectiva da proposta de apoio social, se as melhoras do estado de saúde desses fiéis não vêm mais do fato de "estarem juntos, de uma forma sistemática e no mesmo espaço físico", do que da ação isolada do líder religioso.

É preciso ainda aprofundar a discussão sobre o fenômeno da emoção. Como foi registrado acima, os investigadores responsáveis pela elaboração da teoria do apoio social trabalham com a premissa de que, se a origem da doença está relacionada com as emoções, sua resolução também está, indicando assim que essa teoria inclui a idéia antiga da unidade corpo-mente. A proposta central do apoio social é que, quando as pessoas sentem que contam com o apoio de um grupo de pessoas (associação, vizinhança, igreja, por exemplo), esse apoio tem o efeito de causar melhora na saúde das pessoas envolvidas.

Corten (1996), no livro Os pobres e o Espírito Santo, afirma que o pentecostalismo se caracteriza pela importância dada à emoção. A própria proposta teológica subordina-se à "experiência emotiva partilhada" pelos crentes. Há uma reivindicação para que haja uma "experiência emotiva", e esse desejo aponta para o encanto e a alegria demonstrados nos cultos, em que os crentes são vistos como pessoas simples, tamanhos são seu júbilo e seu entusiasmo. A grande contradição, para muitos dos observadores das classes médias, é que se trata de pessoas que freqüentemente vivem na miséria, na doença e em ambientes repletos de violência, e, no entanto, experimentam essa intensa alegria de estarem vivas. Corten relata que alguns pastores acreditam que as curas geralmente acontecem quando os males não são físicos, mas localizam-se na esfera psicossomática, na qual a resolução não passa por medicamentos. Frequientemente trata-se de emoções de consolo em face de males que não podem ser mudados. Assim, a dignidade do ser humano é o que acaba se afirmando. Outras religiões que realizam uma discussão mais intelectualizada acabam por encarar os cultos pentecostais como se tratando de um misti- 
cismo arcaico. Neste sentido, nada se resolve, nada termina bem, a não ser a percepção de que essa emoção é um sinal da dignidade que o pentecostal possui. A idéia corrente na sociedade de que o pentecostal vira suas costas para o "mundo" significa realmente virar as costas para o demônio (termo freqüentemente utilizado como uma metáfora para rejeitar as doenças, a pobreza, a desigualdade, a violência), não significando necessariamente uma posição fatalista, já que é necessário combater o demônio: virar as costas para o mundo capitalista de competição e modernização para construir redes de solidariedade em que, segundo Corten, doam-se roupas e alimentação, acham-se empregos para os mais necessitados e convidam-se regularmente os irmãos esmagados pela pobreza para jantar em sua casa. Surgem cursos de alfabetização nas igrejas onde os fiéis analfabetos sentem o desejo de ler os salmos que cantam.

No entanto, as muitas formas de combate ao estresse que foram colocadas acima não devem ser ignoradas por quem se interessa pela questão da religião e classes populares. Os resultados das novas terapias de relaxamento e meditação têm sido notáveis e reforçam a lógica interna de uma proposta como a do apoio social. Em dois livros - Inteligência emocional e Emoções que curam -, Goleman (1995 e 1999) oferece vários exemplos de como essas terapias produzem melhoras de saúde, independentemente das condições de vida dos pacientes. A questão central dessas terapias é o trabalho desenvolvido com as emoções. O autor afirma que, quando uma pessoa sofre muito estresse, é liberada a adrenalina; mas se o estresse é constante, a liberação sistemática da adrenalina acaba prejudicando as células imunes, chegando ao risco de o processo ser permanente. Ansiedade crônica, longos períodos de pessimismo, hostilidade e cinismo são estados de espírito tão graves quanto fumar muito ou registrar alta taxa de colesterol. Dores de cabeça, úlceras, artrite, asma e problemas do coração são algumas das doenças que podem surgir a partir desses estados de espírito negativos. Isolar-se socialmente, sem ter com quem conversar de forma íntima, pode representar perigo para a saúde tão sério quanto a obesidade, a falta de exercício físico ou altas taxas de colesterol.

Em seus livros, Goleman discute a importância tanto de olhar de maneira otimista para o mundo, como de contar com o apoio sistemático de alguns amigos. Falar dos seus problemas financeiros e de sua insegurança no emprego frequientemente é mais importante para manter a saúde do que somente eliminar a pressão arterial alta ou reduzir a taxa alta de colesterol. Essas assertivas são acompanhadas do relato de casos que comprovam as posições do autor.

Três desses casos são exemplares. O primeiro refere-se a uma pesquisa envolvendo homens que tiveram o primeiro ataque de coração: dos 120 homens investigados, 25 foram escolhidos por sua perspectiva de vida pessimista e 25 por sua perspectiva de vida otimista. Depois de os 50 homens terem sido acompanhados durante oito anos, verificou-se que 21 dos pessimistas e apenas seis dos otimistas tinham morrido. Os investigadores concluíram que a perspectiva com que se olha o mundo é melhor prognóstico do desenvolvimento da saúde de uma pessoa do que outros fatores mais reconhecidos, como taxa de colesterol, pressão arterial etc.

A segunda investigação, realizada na Universidade de Stanford, demonstrou que mulheres com câncer de mama em estágio avançado, mas que freqüentavam reuniões semanais com seus pares, tiveram o dobro de sobrevida que mulheres que enfrentavam a doença por conta própria. Na mesma lógica, idosos que sofrem ataques do coração, mas que mantêm uma relação íntima com duas ou três pessoas, têm mais possibilidade de sobreviver mais do que um ano depois do ataque, do que os doentes sem essas relações íntimas.

Nosso intuito, ao relacionarmos emoção e pentecostalismo, e logo em seguida discutirmos sobre melhoras de saúde a partir de exemplos de apoio social ou terapias que procuram desenvolver paz de espírito, melhor auto-estima e visão otimista da vida, foi levantar a seguinte questão: é possível que as emoções que estão presentes nos cultos pentecostais gerem resultados semelhantes àqueles apresentados nos 
livros do Goleman? É claro que as obras desse autor são parte de uma vasta produção que procura relacionar a mente com a saúde do corpo humano. O que se quer discutir aqui é se "as emoções que curam", debatidas pelo budismo e pela ciência, são semelhantes às emoções que se encontram presentes nos cultos do pentecostalismo.

Certamente há questões metodológicas a serem enfrentadas. Grosso modo, os cientistas que trabalham com a unidade mente-corpo são oriundos dos países centrais e investigam populações que têm padrão de vida superior ao das classes populares do Brasil e, em particular, das classes populares que freqüentam os cultos pentecostais. Como foi registrado anteriormente, a busca por melhorias de saúde por terapias ditas alternativas é ainda essencialmente uma discussão das classes médias e altas no Brasil. O próprio Goleman, ao discutir a proposta de que lidar melhor com sentimentos negativos é uma forma de prevenção contra doenças, faz apenas uma alusão genérica aos pobres. Comenta, de passagem, que os muito pobres, as mães solteiras e os moradores de bairros com alto índice de crimes, cujas condições de vida fazem com que vivam sob muita tensão, "melhorariam de saúde se tivessem ajuda para lidar melhor com o custo emocional devido ao estresse", o que indica que sua atenção está voltada principalmente para populações com melhores condições de vida.

O que se propõe metodologicamente é uma "tradução", isto é, uma adequação da literatura sobre mente e corpo às condições de vida das classes populares brasileiras. Por exemplo: lembrando a investigação acima relatada sobre visões de mundo otimistas e pessimistas, como adequar essas perspectivas positivas e negativas às condições de vida de moradores de favelas do Rio de Janeiro, onde a insegurança sobre conseguir ou manter um trabalho remunerado é vivida num clima de violência caracterizado por embates entre a polícia e os narcotraficantes?

Quanto aos cultos pentecostais, será que pela própria maneira como são conduzidos - com gritos e músicas barulhentas que contribuem para que o estado emocional seja intenso - eles não são ritos que re- fletem as condições de vida dessas populações que freqüentemente vivem num estado de pobreza e incerteza agudas? Embora membros das classes médias também freqüentem os cultos pentecostais, o pentecostalismo, como diz Corten (1996), "aparece como uma religião dos pobres [...] e a emoção religiosa produz [...] a categoria de pessoa simples".

\section{Apenas uma questão de apoio social ou de outra lógica?}

É preciso ter cuidado com a pretensão de querer compreender a religiosidade popular exclusivamente a partir da lógica da teoria do apoio social. Certamente, essa teoria tem muito a nos ensinar sobre as formas de lidar com o "sofrimento difuso" ou com as doenças crônicas, mas deve-se ter cautela em utilizar essa lógica como única forma de explicar a busca de igrejas e religião pelas classes populares. Tal metodologia pode resultar no ajustamento de um fenômeno muito complexo a uma teoria que ajuda muito, mas não necessariamente dá conta de todas as variáveis envolvendo as classes populares e a religiosidade popular.

Cristian Parker (1996) sugere que a reinterpretação do processo de modernização na América Latina deve contribuir para a compreensão da religiosidade popular manifestada pelas classes populares. Como se sabe, o processo de modernização ocorreu com a introdução da industrialização, juntamente com a melhora significativa dos meios de comunicação e transportes, no fim do século XVIII e no início do século XIX, principalmente nos Estados Unidos e na Europa Ocidental. Neste sentido, esse processo foi parte integrante da revolução industrial e obedeceu a uma lógica baseada principalmente nos insumos da ciência e da racionalidade técnica. Para essa discussão, é importante considerar que o processo de modernização que se desenvolveu nos Estados Unidos e na Europa Ocidental resultou no que se pode chamar de produção de um conforto mínimo para a maioria das populações daquelas regiões do mundo. Por essa razão, diz- 
se que, no bojo do processo de modernização, ocorreu também o fenômeno da secularização. A secularização pressupõe a relativização e a secundarização da religiosidade como visão de mundo, justamente pela crescente hegemonia do método científico e da racionalidade técnica, e da incorporação da maioria da população na sociedade de consumo.

A modernização na América Latina acontece de forma diferente da que ocorreu nos Estados Unidos e na Europa: seus resultados não representam uma melhoria das condições de vida da maioria da população. Em virtude disso, as mudanças na mentalidade religiosa não implicam, como Parker observa, relativização ou secundarização da fé das classes populares, ou seja, apesar de todas as mudanças, em um país como o Brasil as classes populares continuam com uma perspectiva religiosa muita profunda, a ponto de esta ser confundida com um sentido comum popular.

Em uma postura crítica relativamente aos discursos modernizantes sobre o prometido progresso para todos, Parker (1996) chama a atenção para o fato de que no bojo dessa nova interpretação existem pesquisas que indicam que a religião popular é uma das características mais importantes da cultura das classes populares latino-americanas. A questão mais fundamental da religiosidade popular é a crença em um Deus pai e criador que não esquece dos seus filhos. Tratase de uma experiência de vida, parte da cultura popular, que explica a vida e sustenta a religiosidade.

Ora, a pobreza e a miséria, às quais as classes populares já estavam sujeitas antes do aparecimento do processo de globalização, vêm se agravando depois do reajuste neoliberal. As duas décadas de ditadura militar e a inflação elevada também contribuíram para que o Brasil se transformasse num país com um dos maiores índices de desigualdade no mundo e para que se instalasse a crise de saúde já referida anteriormente. O resultado do enorme crescimento do desemprego combinado com a miséria é, de acordo com Parker, a imagem de um mundo que não mais permite mudanças para as classes populares, ou seja, na concepção das classes populares, há poucas evidências de que um dia elas poderão sair do estado de pobreza.
O intenso incentivo a consumir faz com que se busque uma saída: ou pelo consumo simbólico, ou seja, televisão e vídeo, seja pelos jogos ou drogas, seja pelas práticas e ritos mágico-religiosos.

Neste sentido, a religião popular pode ser descrita como forma particular e espontânea de expressar os caminhos que as classes populares escolhem para enfrentar suas dificuldades no cotidiano. Esta observação de Parker pode ser uma pista para que se compreenda uma suposta "falta de interesse" das classes populares pelas questões políticas e pelos partidos chamados progressistas. Há "falta de interesse", ou há a possibilidade das classes populares quererem manter distância porque os políticos não compreendem sua cultura, principalmente no tocante à religiosidade popular?

Diante dessa visão das classes populares - de que há pouco espaço para elas saírem da pobreza -, a religião popular desempenha culturalmente vários papéis: cria uma identidade mais coesa entre as classes populares, ajuda a enfrentar as ameaças, a ganhar novas energias na luta pela sobrevivência, e reforça uma resistência cultural que, por si só, reforça também a busca da religião como solução.

Assim, a questão religiosa das classes populares não deve ser vista como uma questão tradicional e arcaica. Não se trata de apenas constatar a freqüência das classes populares às igrejas, mas de perceber esse fenômeno em um sentido cultural, ou seja, do ponto de vista de grandes parcelas das classes populares há, de fato, uma providência divina.

Em proposta semelhante à de Martins (1989), Parker vê a religiosidade popular como protesto simbólico, principalmente em face de conjunturas nas quais outras formas de protesto não são vistas e sentidas por elas como possíveis. Neste sentido, esse "protesto" não é sempre visível; trata-se de estratégias de sobrevivência de que as classes populares lançam mão dentro de uma sociedade que lhes nega oportunidade de trabalho e o exercício de seus legítimos direitos. A busca pelo sobrenatural, então, tem a ver com a solução de problemas imediatos e cruciais, e não com um investimento para uma vida depois da morte. A fé em 
Deus e na Virgem Maria oferece um sentido para a vida. $\mathrm{O}$ espaço das manifestações religiosas (igreja, centro, templo) oferece uma eficácia simbólica; lá as classes populares podem buscar consolo e encontrar energias morais para enfrentar a incerteza permanente de como superar a falta de trabalho e de comida. Trata-se, nas igrejas pentecostais, daquilo que Corten (1996) denomina "emoção do consolo".

A fome e a miséria são tão agudas que as classes populares freqüentemente vivem no que Parker chama de "imediatismo", "presentismo". Nesse estado, a busca do sobrenatural para a subsistência da família é uma forma de solução adequada à realidade. Assim, como na discussão sobre as categorias de "previsão" e "provisão", não se pensa no futuro (previsão) porque todas as energias estão mobilizadas para evitar a sensação de fome que já havia no passado e garantir a subsistência no dia de hoje (provisão). E a busca da ajuda "sobrenatural", na realidade, é também estratégia de sobrevivência, pois alivia as tensões e angústias, permitindo que se busquem soluções concretas para, pelo menos imediatamente, preservar a vida. $\mathrm{Na}$ visão de Parker (1996), recorre-se à Virgem Maria como forma de garantir energias para superar o momento de desespero, e não como meio de garantir espaço na vida depois da morte.

Cabe lembrar, no entanto, que essa busca de sobrevivência pela via do sobrenatural não exclui a crença de que há uma vida depois da morte. Certamente muitos mediadores da classe média poderiam perguntar se tal comportamento de muitas pessoas das classes populares não impede que haja uma visão política mais combativa e uma organização capaz de pressionar as autoridades a tomarem as medidas necessárias para atenuar essa miséria e pobreza agudas. Mas essa busca do sobrenatural para resolver os problemas urgentes pode culturalmente ser a forma mais "racional" de agir, diante de uma avaliação da "política" como sendo a forma das classes dominantes garantirem seus privilégios.

Se reconhecermos que a religiosidade popular, de fato, é parte integrante da cultura das classes populares, faz sentido a afirmação de Luz (1996) de que os pobres continuam até hoje com uma cosmovisão que entende que os homens não são separados da natureza e que o corpo não se separa da alma - uma visão aparentemente tradicional, que paradoxalmente coincide com a concepção hoje em discussão, de que as doenças têm sua origem no desequilíbrio emocional causado pelo estresse, a partir dos muitos problemas de sobrevivência que as classes populares enfrentam.

Da perspectiva de uma educação popular transformadora, é necessário distinguir entre as propostas de saúde alternativa "individualizantes", das classes média e alta, e os caminhos coletivos das classes populares, criados a partir das suas condições de vida. Os caminhos alternativos de que as classes populares lançam mão para aliviar seus problemas de saúde certamente são diferentes: tanto pela questão da unidade corpo-mente, quanto pela perspectiva do apoio social, o caminho da espiritualidade e da religião revela-se como uma das trajetórias principais. A questão que apontamos anteriormente, de "não engolir sapos" ou de desabafar, pode ser uma pista para se compreender melhor o "uso" que as classes populares fazem das igrejas, especialmente as igrejas que desenvolvem cultos em que o gritar e o cantar alto é uma constante. O curta-metragem Santa Cruz, de João Salles, demonstra bem a autonomia com que os moradores de um bairro periférico de Santa Cruz, município do Rio de Janeiro, tomaram conta da igreja iniciada pelo ex-metalúrgico e agora pastor Jamil. Esse pastor tem o forte desejo de um dia poder participar dessa "entrega ao Espírito Santo", para poder também entrar em transe e acumular energias morais para enfrentar os problemas de sobrevivência. Por enquanto, desempenha a tarefa de administrar a igreja, abrindo e fechando as portas para uma população que já sabe o que procurar naquele espaço.

Segundo Cox (1995), se a nossa época está voltada para os fantásticos progressos da pesquisa científica relacionada com a medicina, isto representa apenas um curto período da história da humanidade (aproximadamente trezentos anos). Durante a maior parte dessa longa história, a magia, a religião e a cura quase sempre andaram juntas. E, certamente, uma das gran- 
des surpresas reservadas à humanidade, durante o século XX, foi o ressurgimento da religião no mundo inteiro. Coincidência ou não, manifesta-se também, na segunda metade do século XX e no início do século XXI, o desencantamento com o que se conhece como medicina moderna ou high tech. Neste sentido, começa a voltar à cena uma complementariedade que existiu durante grande parte da história da humanidade: a da religião com a saúde. ${ }^{3}$

É freqüente que os mediadores progressistas militantes, profissionais, políticos - demonstrem dificuldades e conflitos com a relação que as classes populares mantêm com a questão religiosa. Se, de um lado, o debate sobre a existência ou não de Deus não parece mais obstáculo nas discussões políticas, por outro, a inclusão da questão religiosa incorpora, com poucas exceções, apenas a proposta da teologia da libertação, defendida no Brasil pelas alas progressistas da Igreja católica. Quando as propostas de outras religiões, tais como as pentecostais ou evangélicas, são abordadas, é freqüente que isso ocorra por um prisma de categorias como as de "manipulação" e "alienação".

No entanto, a dificuldade de compreender o que os membros das classes populares estão dizendo ou fazendo - por exemplo, no caso das igrejas já referidas - pode bem estar relacionado mais com um problema de postura do que com questões técnicas como, por exemplo, questões lingüísticas. A questão de postura estaria relacionada com a dificuldade em aceitar que as pessoas humildes, pobres, moradoras da periferia, são capazes de produzir conhecimento, são capazes de organizar e sistematizar pensamentos sobre a sociedade e, dessa forma, fazer opções que apontem para possíveis melhorias para suas vidas.

É bem provável que estes setores da população tenham uma enorme lucidez sobre sua situação so-

\footnotetext{
${ }^{3}$ Tudo indica que há vários fatores contribuindo para a volta desta relação, entre eles a urbanização massiva que vem ocorrendo no planeta, principalmente a partir das migrações, o que significa para muitos a perda de um lugar seguro no campo ou no interior e a necessidade de recompor a vida e a identidade.
}

cial. Mas clareza sobre sua situação social pode significar também clareza de que uma melhora significativa seja uma ilusão. Neste sentido, a crença em melhoras e em soluções mais efetivas para a pobreza pode ser apenas um desejo, embora importante, dos mediadores comprometidos das classe médias.

Se a argumentação acima procede, é possível que um dos grandes problemas para os profissionais, pesquisadores e militantes seja a forma como as classes populares encaram sua vida, existência marcada, cercada de pobreza e sofrimento. É possível que a relação que os profissionais freqüentemente estabelecem com essa população acabe sendo uma cobrança de busca permanente de sobrevivência mais racional e eficiente. A frase tão conhecida dos Titãs: "A gente não quer só comer, a gente quer prazer para aliviar a dor" pode estar indicando, no entanto, outro enfoque. Neste sentido, a construção de aparências, que pode ser entendida como a construção de sonhos, não deve ser vista apenas como forma de "escapar da realidade", mas como a indicação de uma concepção mais ampla de vida. "Prazer para aliviar a dor", então, pode tomar vários sentidos para as classes populares, distintos dos sentidos que têm para as classes médias. Um desses sentidos, certamente, é o de que vale a pena viver a vida, mesmo a partir da perspectiva de que não se pode vislumbrar uma saída para o sofrimento e a pobreza que se atura diariamente. Se, de um lado, este enfoque pode ajudar a compreender por que é possível passar fome para comprar um aparelho de televisão ou para experimentar o êxtase com o futebol, o álcool ou os jogos de azar, de outro lado ele também ajuda a compreender por que as religiões, sejam elas o pentecostalismo, o catolicismo popular, o espiritismo kardecista ou as afro-brasileiras, oferecem muitas vezes uma eficácia simbólica de resultados concretos em matéria de bem-estar.

Martins (1989) observa que Satriani trabalha a idéia de que a cultura popular, para poder afirmar-se neste mundo do vencedor, utiliza a duplicidade, o "duplo código", em que o afirmar e o negar, o dizer e o desdizer, a interpretação coerente e a ilusão encontram-se na mesma frase. Ou, como diz Chaui (1990), 
é possível que haja uma profunda inconformidade escondida atrás de uma postura de fatalismo.

Martins sugere também que a cultura popular é uma teoria imediata, com um conhecimento já acumulado que permite que as classes populares sistematizem, interpretem e expliquem a realidade. Neste sentido, o aparente absurdo para o profissional é de uma lógica clara para as classes populares.

Finalmente, a idéia da cultura popular como memória de alternativas deveria ser pensada no contexto da dificuldade que grande parcela dos pobres tem de poder agir somente dentro de um quadro previamente delimitado. Tem sentido, então, a mudança na forma de milagre, ou, como pensa Chaui (1990), a possibilidade de uma realidade no interior da existente. Para desespero de muitos pastores protestantes e padres católicos, trata-se do rompimento da ordem prevista, por um esforço da imaginação.

\section{Conclusão}

Embora seja importante procurar compreender o fenômeno da religiosidade popular através da proposta do apoio social e através da cultura popular, é necessário certo cuidado em utilizar exclusivamente essas abordagens. Trata-se de abordagens que têm como ponto de partida a investigação científica, e não há como negar que isso é relevante. Há contribuições valiosas de vários pesquisadores, em particular de Machado (1996), sobre as melhoras econômicas no interior das famílias pentecostais e evangélicas, entre elas a renúncia à bebida e ao fumo, como também a descoberta feita pela mulher evangélica de que ganha em autonomia quando vai à igreja à noite, desacompanhada, e quando trabalha fora de casa. São certamente insumos importantes para compreender as mudanças que ocorrem nessas famílias, a partir da sua adesão a essas igrejas.

Mas há outras questões que ficam pouco claras. Trata-se do que Cesar e Shaull (1999) chamam de dimensão do transcendente, que permeia o pentecostalismo e outras religiões populares: o encantamento e a alegria diante de uma vida de muitas dificuldades e sofrimentos, sem grandes perspectivas de realização profissional e familiar na forma como esse termo é compreendido entre os membros das classes médias. Neste sentido, Cesar e Shaull afirmam que possivelmente o maior milagre que se realiza no interior da proposta da religião popular é a própria sobrevivência diante de tanta miséria e opressão. Essa dimensão espiritual e transcendental de que falam os autores acaba, contraditoriamente, favorecendo uma autonomia que corresponde ao que os teóricos do apoio social chamam de "controle sobre o seu próprio destino".

Cesar e Shaull, entretanto, insistem: o que está em discussão não é apenas a prática sistemática de solidariedade e ajuda mútua, que explica em parte a sobrevivência de muitos, mas uma postura aparentemente alienante, que talvez seja o que Parker (1996) chama de resistência e refúgio, um sutil protesto ante governos cujas decisões políticas não são entendidas, pois a questão social é, quando muito, um complemento, um apêndice, e não o eixo central das suas propostas.

Como compreender o que Cesar e Shaull indicam como resistência sobre-humana às muitas adversidades resultantes dos governos autoritários e insensíveis? Como compreender o que denominam um "espetáculo de êxtase", produzindo manifestações tanto pessoais como coletivas, nas quais, freqüentemente, como no caso do pastor Jamil de Santa Cruz, os pastores tornam-se espectadores?

Será que nós, mediadores, professores, pesquisadores, educadores populares, não estamos diante do que José Souza de Martins chama de "crise de interpretação", crise de interpretação que é nossa? Tratase de uma discussão desenvolvida por Martins (1989) sobre as dificuldades que os profissionais, técnicos e professores, geralmente oriundos da classe média, têm de compreender a fala e o fazer das classes populares. Relacionando essas observações do autor com a questão da religiosidade popular dos pobres, lembramos uma das premissas de sua discussão: os membros das classes populares produzem conhecimentos e fazem uma avaliação da realidade, e nossa dificuldade é compreender a lógica com que isso é feito. 
Neste sentido, é necessário acreditar que as classes populares sabem o que faz bem para elas, independentemente da nossa compreensão das suas escolhas. Assim, entender o pensamento dos pentecostais não depende de estarmos ou não de acordo com o que eles pensam e fazem. Nós, os mediadores, professores e técnicos, mesmo com todas as nossas dificuldades materiais, representamos o espaço da garantia e do privilégio, e os pobres representam o espaço da sobrevivência.

VICTOR VINCENT VALLA é pesquisador titular do Departamento de Endemias Samuel Pessoa, na Escola Nacional de Saúde Pública da Fundação Oswaldo Cruz, professor da Faculdade de Educação da Universidade Federal Fluminense e membro do Centro de Estudos e Pesquisas da Leopoldina (CEPEL). Últimas publicações: A crise da compreensão é nossa; procurando compreender a fala das classes populares (Educação e Realidade, Porto Alegre: UFRGS, v. 22, nº 2, 1997, p. 177-191); Apoio social e saúde; buscando compreender a fala das classes populares (In: COSTA, M.V., org.). Educação popular hoje. São Paulo: Loyola, 1998, p. 151-180). Organizou: Saúde e educação (Rio de Janeiro: DP\&A, 2000) e Cultura popular e religião (Rio de Janeiro: DP\&A, 2001). E-mail: valla@ensp.fiocruz.br.

\section{Referências bibliográficas}

BERMANN, S., (1995). Trabajo precario e salud mental. Cordoba: Navajo Editor.

CESAR, W., SHAULL, R., (1999). Pentecostalismo e futuro das igrejas cristãs; promessas e desafios. Petrópolis, RJ: Vozes / São Leopoldo, RS: Sinodal.

CHAUI, M., (1990). Notas sobre cultura popular. In: CHAUI, M. Cultura e democracia. São Paulo: Cortez.

CORTEN, A., (1996). Os pobres e o Espírito Santo; o pentecostalismo no Brasil. Petrópolis, RJ: Vozes.

COX, H., (1995). Fire from heaven; the rise of pentecostal spirituality and the reshaping of religion in the twenty-first century. New York: Addison-Wesley.
FERNANDES, Ruben Cesar, (1994). Privado porém público; o terceiro setor na América Latina. Rio de Janeiro: RelumeDumará.

FINKLER, K., (1985). Spiritualist healers in Mexico; successes and failures of alternative therapeutics. New York: Praeger.

GOLEMAN, D., (1995). Inteligência emocional. New York: Bantam Books.

(org.) (1999). Emoções que curam; conversas com o Dalai Lama sobre mente alerta, emoções e saúde. Rio de Janeiro: Rocco.

LUZ, M. T., (1996). A arte de curar versus a ciência das doenças. São Paulo: Dynamis.

MACHADO, M. D. C., (1996). Carismáticos e pentecostais; adesão religiosa na esfera familiar. São Paulo: Anpocs/Campinas, SP: Autores Associados.

MARIZ, C. L., MACHADO, M. D. C., (1994). Pentecostalismo e a redefiniçãa do feminino. In: LANDIN, L., (org.). Pentecostes e nova era; fronteiras, passagens. Rio de Janeiro: Instituto Superior de Religião (ISER). (Série Religião e Sociedade, 17/ 1-2.)

MARTINS, J. S., (1989). Dilemas sobre as classes subalternas na idade da razão. In: MARTINS, J. S. Caminhada no chão da noite. São Paulo: Hucitec.

MCEWEN, B. S., (1998). Protective and damaging effects of stress mediators. The New England Journal of Medicine, v. 338, $\mathrm{n}^{\circ} 3$, p. 171-79, jan. 15 .

PARKER, C., (1996). Religião popular e modernização capitalista; outra lógica na América Latina. Petrópolis, RJ: Vozes.

VALLA, V. V., (1999a). Educação popular, saúde comunitária e apoio social numa conjuntura de globalização. Cadernos de Saúde Pública, Rio de Janeiro, Suplemento 1.

(1999b). As respostas do movimento popular ao "estado de emergência permanente". In: VALLA, V. V., STOTZ, E.N. (org.), Educação, saúde e cidadania. $2^{\text {a }}$ ed. Petrópolis, RJ: Vozes. p. 87-98. 
not by his/her activity but by the readiness to be transformed by experience - a human passageway, submitted to a logic of passion. It affirms that the knowledge of experience is acquired in the relationship between knowledge and human, singular concrete life.

Key-words: experience, knowledge of experience, experience/sense.

Lílian do Valle

Bases antropológicas da cidadania brasileira: sobre escola pública e cidadania na Primeira República Devido às fragilidades de sua implantação, não são poucos, no Brasil, a tratarem o regime republicano como uma simples continuação do período monárquico. Igualmente correntes, as críticas à tradição de constituição, no país, de um Estado forte e monopolizador, concedem cores de fatalidade à idéia da formação histórica de um cidadão inexoravelmente passivo, tipo antropológico definitivo, a marcar os rígidos limites à democratização da sociedade brasileira. Seria, assim, cabal a impossibilidade de a escola pública formar cidadãos - todos os argumentos em contrário consistindo apenas em novas reedições do velho mito da demiurgia educacional? Ao tentar reunir os elementos para análise das construções antropológicas que estão na base da experiência de cidadania brasileira, esse artigo coloca em perspectiva aquela que sem dúvida é a primeira e a mais central das exigências democráticas: a afirmação incondicional e incondicionada da igualdade política dos cidadãos. Palavras-chave: escola pública, Primeira República, cidadania.

\section{Anthropological bases of Brazilian} citizenship: on the public school and citizenship in the $1^{\text {st }}$ Republic Many critics treat the republican regi- me in Brazil as a simple continuation of the monarchic period due to the fragility of its implantation. Critics of the tradition of the creation of a strong monopoly state in the country are equally common-place and accord tones of fatality to the idea of the historical formation of an inexorably passive type of definitively anthropological citizen, setting rigid limits to the democratisation of Brazilian society. The impossibility of the public school forming citizens would thus be proven - all the arguments to the contrary consisting only of re-editions of the old myth of the educational demiurge? By attempting to unite elements capable of analysing these anthropological constructions which form the base of the experience of Brazilian citizenship, this article brings into perspective what is without a doubt the first and most central of democratic requirements: the unconditional and unconditionable affirmation of the political equality of citizens.

Key-words: Public school, $I^{s t}$ Republic, citizenship.

\section{Nora Krawczyk}

\section{A sustentabilidade da reforma} educacional em questão: a posição dos organismos internacionais $\mathrm{O}$ artigo discute temas e questões abordados pelas produções dos organismos internacionais a partir de 1998 como diferentes dimensões de sustentabilidade das reformas educacionais na América Latina, que oferecem interessantes indícios dos aspectos que receberam e continuarão recebendo investimentos - técnicos e financeiros desses organismos. Pelo menos três dimensões preocupam bastante os organismos internacionais: a dimensão política, a dimensão financeira e a dimensão técnica. Para sua análise, fo- ram examinadas as publicações do Banco Mundial, da CEPAL, do PREAL, do BID, do IIPE/UNESCO e da OREALC/UNESCO, desde 1998 até 2001.

Palavras-chave: reforma educacional, América Latina, organismos internacionais.

The sustainability of the educational reform in question: the position of the international organisations

This article discusses the themes and questions dealt with in the productions of international organisations from 1998 onwards with relation to different dimensions of the sustainability of the educational reforms in Latin America which offer interesting signs of those aspects which have and will continue to receive technical and financial investments from such organisations. At least three dimensions concern the international organisations: the political, the financial and the technical dimensions. This analysis is based on an examination of publications by the World Bank, CEPAL, PREAL, BID, IIPE/ UNESCO and OREALC/UNESCO, from 1998 to 2001.

Key-words: educational reform, Latin America, international organisations.

Victor Vincent Valla

Pobreza, emoção e saúde: uma discussão sobre pentecostalismo e saúde no Brasil

No campo de educação e saúde tem surgido um debate sobre a origem dos problemas de saúde, o qual propõe que a origem desses problemas está basicamente relacionado com as emoções mais do que com bactérias ou vírus. A teoria do apoio social sugere que, se as emoções são relacionadas ao surgimento das doenças, as soluções também estão relacionadas com 
as emoções. As chamadas terapias alternativas são propostas para lidar com as emoções, juntamente com a teoria do apoio social. Esta teoria propõe que quando pessoas recebem apoio emocional ou material sistemático de grupos ou instituições, este apoio é benéfico para a saúde dessas pessoas. A hipótese levantada é que o custo das terapias alternativas, juntamente com as dificuldades do sistema público de saúde em lidar com os sofrimentos dos pobres, ajuda a explicar o grande crescimento das igrejas pentecostais e evangélicas em torno das classes populares no Brasil.

Palavras-chave: pobreza, saúde e emoção, pentecostalismo.

Poverty, emotion and health: a discussion on Pentecostalism and health in Brazil

In the field of health and education, a debate has arisen about the causes of health problems. This debate maintains that the origin of health problems today is basically related to the emotions rather than viruses or bacteria. The theory of social support suggests that if the causes of health problems are basically emotional, then the solutions must also be related to the emotions. The so-called alternative therapies are proposed as a way of dealing with the emotions, together with the theory of social support. This theory holds that when people receive systematic emotional or material support from groups or institutions, this support is beneficial to their health. This raises the hypothesis that the cost of alternative therapies together with the difficulties encountered in the public health system in dealing with the sufferings of the poor help to explain the enormous growth of Pentecostal and evangelical churches among working-class populations in Brazil.
Key-words: poverty, emotion and health, Pentecostalism.

\section{Ana Lúcia Valente}

\section{Os negros, a educação e as políticas}

\section{de ação afirmativa}

Este texto procura avançar na compreensão do movimento histórico que subjaz a implementação de políticas de ação afirmativa para os negros no campo educacional, considerando ser essa a condição para o atendimento dos interesses e necessidades desse grupo, na perspectiva da transformação. Para isso, são retomadas reflexões realizadas em outras oportunidades, explicitando idéias há muito debatidas por estudiosos e militantes negros, bem como discutindo os momentos em que as diferenças são transformadas em "problema", quando são marcas distintivas e necessárias da condição humana. Em seguida, busca-se avaliar as condições materiais e ideológicas do capitalismo atual, o processo de etnicização da força de trabalho e o deslocamento do debate para a esfera cultural/ educacional promovido por organismos internacionais.

Palavras-chave: negros e educação, políticas de ação afirmativa.

\section{Negroes, education and policies of affirmative action}

This text seeks to further our understanding of the historical movement which underlies the implementation of policies of affirmative action for Negroes in the field of education considering this to be the condition for attending the interests and needs of this group, in the perspective of transformation. To this end, the text takes up reflections developed on other opportunities explaining ideas debated for years by scholars and militant Negroes and discussing the moments in which differences are transformed into a "problem", when they are in fact distinctive and necessary marks of the human condition. Thereafter, we seek to evaluate the material and ideological conditions of present day capitalism, the process of 'ethnicisation' of the work force and the dislocation of the debate from the cultural/ educational sphere promoted by international organisations.

Key-words: negroes and education, policies of affirmative action.

Alda Judith Alves-Mazzotti

Repensando algumas questões sobre o trabalho infanto-juvenil

$\mathrm{O}$ artigo focaliza algumas questões presentes na discussão acadêmica sobre o trabalho infanto-juvenil e suas consequiências sobre o "fracasso escolar" das crianças pobres, buscando apontar posicionamentos ideológicos, sociocentrados, e falhas metodológicas que levam à redução da complexidade do problema. Tal redução evidencia-se no estabelecimento de relações lineares que desconsideram as mediações envolvidas, bem como na homogeneização de categorias que incluem uma vasta gama de variações internas. São apresentados exemplos de pesquisas que sustentam os questionamentos feitos, apontando-se algumas consequiências daqueles posicionamentos reducionistas sobre as práticas escolares e o desenvolvimento cognitivo e afetivo das crianças e adolescentes trabalhadores. Dentre os fatores que precisam ser considerados na discussão das relações entre trabalho precoce e trajetória escolar são destacados: as mediações representadas pelas diversas instâncias excludentes que cercam a pobreza, a heterogeneidade do trabalho infanto-juvenil e o papel atribuído às famílias pobres com relação ao 